\title{
What are hospitals doing about clinical guidelines?
}

\author{
Edward B Renvoize, Susan M Hampshaw, Jane M Pinder, Phil Ayres
}

United Leeds Teaching Hospitals NHS Trust, Department of Clinical Audit, The General Infirmary at Leeds, Great George Street, Leeds, UK Edward B Renvoize, consultant in clinical audit

Susan M Hampshaw, formerly senior clinical audit officer

Jane M Pinder, clinical audit development manager

\section{St James's and} Seacroft Teaching Hospitals NHS Trust, Effective Practice Unit, St James's University Hospital, Beckett Street, Leeds, UK

Phil Ayres, consultant in epidemiology and public health

Correspondence to: Dr Edward Renvoize, Department of Research and Development, Blackpool Wyre and Fylde Community Health Service NHS Trust, Lytham Hospital, Warton Street, Lytham FY8 5EE, UK.

Accepted for publication 1 October 1997

\begin{abstract}
Objectives-To assess the attitudes of senior hospital staff towards clinical guidelines, and to ascertain the perceived extent and benefits of their local use; to identify those hospitals with current or planned future written strategies for the systematic development of clinical guidelines, and the staff responsible for leading them; and to establish the essential elements of existing strategies, and the methods used to ensure the proper development, dissemination, implementation, and evaluation of local guidelines.
\end{abstract}

Design-Cross sectional survey.

Participants-Senior staff of 270 acute hospitals in the United Kingdom (response rate 202/270 (75\%)) in 1995.

Results-197/199 (99\%) of respondents thought that clinical guidelines were a good idea, and 176/196 (90\%) were aware of some guideline activity occurring within their hospitals. The most important benefits of local guideline activity were increased healthcare efficiency and effectiveness, greater consistency of treatment, and team building. 174/194(90\%) of respondents were in favour of the development of a readily accessible national repository of evidence-based clinical guidelines. 38/201 (19\%) of respondents had a clinical guidelines strategy and a further 91/201 (45\%) said that they had plans to develop one in the near future. The need to improve clinical outcomes was most often reported as the reason for developing a strategy. Medical directors most commonly had formal responsibility to lead the strategy, but someone without formal responsibility ran the operation in half the hospitals. Only $18 / 36(50 \%)$ of strategies gave advice on the development of guidelines; and only a few strategies made explicit statements on which clinical services to target for guideline development, or the methods to be used for their validation and promotion. Some strategies lacked explicit statements on methods to monitor adherence, routine review, and update of guidelines. Internal literature searches $(29 / 31(94 \%))$, the use of national guidelines $(29 / 32(91 \%))$, local consensus conferences $(28 / 32(88 \%))$, and peer group review $(21 / 24(88 \%))$ were the most popular methods of validation used in hospitals with a strategy. Methods used to promote the dissemination, implementation, and evaluation of clinical guidelines included clinical audit (31/32 (97\%)), peer review (25/30 (83\%)), continuing edu- cation (23/29 (79\%)), targeting of opinion leaders $(17 / 26(65 \%))$, use of structured case notes $(14 / 31(45 \%))$, patient mediated interventions $(9 / 26(35 \%))$, and patient specific reminders $(8 / 26(31 \%))$.

Conclusions-Most senior hospital staff have a favourable attitude towards clinical guidelines. Most hospitals are undertaking some guideline activity, but few seem to be doing so within a locally agreed hospital wide strategy in which guideline development, dissemination, implementation, and evaluation are systematically considered. Many of the current methods used to validate guidelines locally are inadequate. Evidence-based clinical guidelines should be developed nationally, leaving hospitals to focus their energies on the local adaptation, dissemination, implementation, and evaluation of such guidelines. Only in this way will local guidelines achieve their full potential to improve clinical care and patient outcomes.

(Quality in Health Care 1997;6:187-191)

Keywords: clinical guidelines; hospitals; strategy; assessment

\section{Introduction}

Clinical guidelines-"systematically developed statements to assist practitioner and patient decisions about appropriate health care for specific clinical circumstances"'-have the potential to improve clinical practice and patient outcomes. ${ }^{2-4}$ However, the extent to which clinical guidelines do this depends crucially not only on how they are developed, but also on how they are disseminated and implemented..$^{2-4}$

The development of a good guideline requires the active participation of key clinical staff, a systematic review of the scientific evidence, the linking of that evidence to the guideline recommendations, and careful attention to other quality criteria - such as clarity and clinical flexibility. ${ }^{15-8}$ Yet, even the most scientifically developed guideline cannot improve patient care unless the staff for whom the guideline is intended are aware of its existence, and are actively influenced to use it in their clinical practice. ${ }^{9-11}$ Promotion of the uptake of guidelines requires leadership, good change management skills, energy, open communication, and time. ${ }^{9}$ The development, dissemination, and implementation of robust clinical guidelines are thus a major undertaking, with considerable organisational implications. ${ }^{12}$

Along with initiatives-such as evidencebased medicine and clinical audit-clinical guidelines play an important part in the 
Table 1 Response rates and job titles of respondents

\begin{tabular}{lc}
\hline & $n(\%)$ \\
\hline Response rate: & $202 / 270(75)$ \\
Completed questionnaires returned & $8 / 270(3)$ \\
Written summary of guideline activity returned & $15 / 270(6)$ \\
Letter refusing to complete a questionnaire returned & $45 / 270(17)$ \\
No response & $86 / 199(43)$ \\
Job title: & $32 / 199(16)$ \\
Medical director & $29 / 199(15)$ \\
Clinical audit staff & $16 / 199(8)$ \\
Director of nursing services/quality & $14 / 199(7)$ \\
Chief executive officer & $12 / 199(6)$ \\
Research/epidemiology/clinical effectiveness staff & $10 / 199(5)$ \\
Specialist staff (eg, integrated care pathway coordinator) & \\
Managers (eg, director of planning) & \\
\hline
\end{tabular}

promotion of clinical effectiveness, a declared key priority for the National Health Service (NHS). ${ }^{13}$ Indeed, the NHS Executive has argued that clinical guidelines are fundamental to ensuring organisation wide quality, ${ }^{15}$ and has recommended that hospitals devise strategies which actively foster and encourage the development of local guidelines. ${ }^{16}$ However, major reservations have been expressed about clinical guidelines, ${ }^{17}{ }^{18}$ and it is not at all clear what senior hospital staff think of them. Neither is it known if hospitals are acting on the NHS Executive's recommendation to develop a clinical guidelines strategy, nor how the issues of development, dissemination, and implementation are being tackled at the grass roots. This prompted us to conduct a postal questionnaire survey of all acute NHS hospitals in the United Kingdom to find out what is happening to clinical guidelines, and the results are reported here.

Our study had the following objectives: to assess the attitudes of senior hospital staff towards clinical guidelines, and to ascertain the perceived extent and benefits of their local use; to identify those hospitals with current or planned future written strategies for the systematic development of clinical guidelines, and the staff responsible for leading them; and to establish the essential elements of existing strategies, and the methods being used to ensure the proper development, dissemination, implementation, and evaluation of local guidelines.

\section{Methods}

After a literature review on clinical guidelines, and interviews with experts on the subject by one of the authors (PA), a questionnaire was

Table 2 Factors influencing decision to develop a clinical guidelines strategy

\begin{tabular}{lllc}
\hline Influence & $\begin{array}{l}\text { Ranked first } \\
(n=34) \\
(n(\%))\end{array}$ & $\begin{array}{l}\text { Ranked second } \\
(n=34) \\
(n(\%))\end{array}$ & $\begin{array}{l}\text { Ranked third } \\
(n=34) \\
(n(\%))\end{array}$ \\
\hline $\begin{array}{l}\text { Improving clinical outcomes } \\
\text { Part of an organisational quality initiative }\end{array}$ & $16(47)$ & $11(32)$ & $3(9)$ \\
$\begin{array}{l}\text { To improve internal consistency of approach to } \\
\text { clinical practice }\end{array}$ & $7(21)$ & $7(21)$ & $11(32)$ \\
$\begin{array}{l}\text { Purchaser pressure } \\
\text { Part of research and development strategy }\end{array}$ & $5(15)$ & $6(18)$ & $4(12)$ \\
$\begin{array}{l}\text { To identify information needs for a clinical } \\
\text { information system }\end{array}$ & $1(3)$ & $1(3)$ & $6(18)$ \\
$\begin{array}{l}\text { Financial pressure } \\
\text { Guidance received from the NHS Executive }\end{array}$ & $1(3)$ & $2(6)$ & $2(6)$ \\
Pressure from nurses & $1(3)$ & $2(6)$ & $0(0)$ \\
Pressure from consultants & $0(0)$ & $2(0)$ & $2(6)$ \\
Pressure from therapists & $0(0)$ & $0(0)$ & $2(6)$ \\
Other & $0(0)$ & $0(0)$ & $1(3)$ \\
\hline
\end{tabular}

designed to elicit the necessary information from hospitals to meet the study's objectives. Face validity of the questionnaire was sought by asking the experts to comment on its structure and content. After these comments, the questionnaire was modified slightly, piloted in 10 randomly selected acute hospitals, and further amended as the result of the pilot experience.

The questionnaire contained 34 questions, divided into five sections (A-E). Each section contained a series of closed (with a box to be ticked for each possible answer) and open ended questions. Respondents without a strategy on clinical guidelines were asked to complete sections A and E only, whereas those with a strategy were asked to complete all five sections.

In section $A$, respondents were asked to identify who they were; if their hospital had a written clinical guidelines strategy; if not, was there a plan to develop one in the near future; and if no plan to do so, did they consider the development of such a strategy in the future a good idea?

In section $\mathrm{B}$, respondents with a strategy were asked to rank the three main influences on their hospital's interest in guideline development from a list of possible influences; to identify who had formal and operational responsibility for leading the strategy and to estimate roughly how much time those with operational responsibility allocated to this task; and to identify the key elements considered in the clinical guidelines strategy.

In section $\mathrm{C}$, respondents were asked if the guidelines used in their hospitals were evidence-based; and if so, who was responsible for validating the evidence, and which validation methods were used.

In section $\mathrm{D}$, respondents were requested to identify any methods used to disseminate, implement, and evaluate local clinical guidelines.

Finally in section E, respondents were asked if they thought that clinical guidelines were a good idea; which healthcare professional groups had the greatest interest in seeing a planned approach to their development and use locally; to assess the perceived extent and benefits of their local use; and if they thought that a national repository of evidence-based clinical guidelines which could be readily accessed should be developed.

For logistical reasons, only acute NHS hospitals (defined as those containing acute medical and surgical beds) in the United Kingdom were surveyed. The addresses of these acute hospitals (total 270), and the names of their chief executives were identified from the 1994-5 Directory of Hospitals and NHS Trusts. ${ }^{19}$ In April 1995, a copy of the questionnaire and an explanatory letter were sent to each chief executive. Those chief executives who were personally unable to complete the questionnaire were asked to pass it on to the person they deemed most appropriate within their hospital for completion. A computerised database of names and addresses was established to facilitate the follow up of nonresponders. Hospitals failing to respond by two 
Table 3 Staff with formal responsibility to lead the clinical guidelines strategy

\begin{tabular}{ll}
\hline Professional group ( $n=35)$ & $n(\%)$ \\
\hline Medical director & $12(34)$ \\
Clinical audit (five chairs of clinical audit & \\
$\quad$ committee and one senior lecturer) & $6(17)$ \\
Clinical effectiveness coordinator & $3(9)$ \\
Clinical management team & $2(6)$ \\
Specialty head & $2(6)$ \\
Director of quality (nursing and midwifery) & $2(6)$ \\
Director of nursing and clinical audit group & $1(3)$ \\
Head of quality and medical director jointly & $1(3)$ \\
Medical director and director of nursing jointly & $1(3)$ \\
Chief nurse and clinical audit physician jointly & $1(3)$ \\
No one & $4(11)$ \\
\hline
\end{tabular}

and four months after the initial posting were sent reminder letters and further copies of the questionnaire. Administrative problems-such as the need to clarify the names and addresses to whom the questionnaire should be sent-were resolved by telephone.

The quantitative data from the questionnaires returned by the end of September 1995 were collated and analysed with spreadsheet software (Lotus 123 for DOS). The qualitative questionnaire responses were analysed separately and grouped under broad themes.

The denominators in the following results vary, being sometimes less than the total number of questionnaires returned. This is because some respondents did not answer all the relevant questions in the questionnaire.

\section{Results}

RESPONSES FROM ALL HOSPITALS, IRRESPECTIVE OF WHETHER OR NOT THEY HAD A CLINICAL GUIDELINES STRATEGY

Completed questionnaires were received from $75 \%(202 / 270)$ of the hospitals surveyed (table $1)$. Ninety two per cent $(183 / 199)$ of the questionnaires were passed on by the chief executive to someone else for completion, usually to the medical director (table 1).

Nineteen per cent $(38 / 201)$ of respondents reported that their hospital had a written strategy to develop clinical guidelines, and a further $45 \%(91 / 201)$ replied that they had plans to develop one in the near future. Of those respondents from hospitals with no plans to develop a strategy, $71 \%(46 / 65)$ thought that developing one in the future was a good idea and $29 \%(19 / 65)$ did not. Ninety nine per cent (197/199) of respondents thought that clinical guidelines were a good idea, and 90\% (176/

Table 4 Key elements addressed in the clinical guidelines strategy

\begin{tabular}{llr}
\hline & Yes $n(\%)$ & No $n(\%)$ \\
\hline Are there explicit statements regarding: & & \\
Whether guidelines should be uni/multidisciplinary? & $24 / 37(65)$ & $13 / 37(35)$ \\
Written advice on how to develop guidelines? & $18 / 36(50)$ & $18 / 36(50)$ \\
How priorities for guideline development are to be determined? & $19 / 35(54)$ & $16 / 35(46)$ \\
Which clinical services are to be targeted? & $12 / 33(36)$ & $23 / 33(70)$ \\
Are there explicit statements regarding the content of guidelines in & & \\
terms of: & & \\
Objectives of clinical care & $25 / 33(76)$ & $8 / 33(24)$ \\
Identification of key clinical activities & $23 / 32(72)$ & $9 / 32(28)$ \\
Standard setting & $23 / 32(72)$ & $9 / 32(28)$ \\
Desired outcomes of clinical care & $22 / 32(69)$ & $10 / 32(31)$ \\
Methods to evaluate the scientific basis of guidelines & $15 / 35(43)$ & $20 / 35(57)$ \\
Methods to promote the uptake of guidelines & $17 / 35(49)$ & $18 / 35(51)$ \\
Methods for monitoring adherence to guidelines & $18 / 34(53)$ & $16 / 34(47)$ \\
Methods for routinely reviewing and updating guidelines & $27 / 37(73)$ & $10 / 37(27)$ \\
\hline
\end{tabular}

196) were aware of some guideline activity occurring within their hospitals.

Professional groups reported by respondents as having the greatest interest in a planned approach to guideline development within their hospitals were doctors $(60 \%, 119 / 199)$, managers $(59 \%, 118 / 199)$, nurses $(58 \%, 115 /$ $199)$, purchasers $(56 \%, 111 / 199)$, and therapists (44\%, 87/199). Respondents identified increased healthcare efficiency $(52 \%, 103 / 199)$ and effectiveness $(51 \%, 101 / 199)$, greater consistency of treatment $(43 \%, 85 / 199)$, and team building $(24 \%, 48 / 199)$ as the most important benefits of local development of clinical guidelines.

Ninety per cent $(174 / 194)$ of respondents were in favour of the development of a readily accessible national repository of evidencebased clinical guidelines.

RESPONSES FROM HOSPITALS WITH A WRITTEN STRATEGY FOR THE SYSTEMATIC DEVELOPMENT OF CLINICAL GUIDELINES

Respondents from 38 hospitals replied that they had a written strategy to develop clinical guidelines; most strategies were developed between 1994 and 1995 by multiprofessional steering groups. The factor most often reported as influencing the decision to develop a strategy was the need to improve clinical outcomes. This was ranked first by almost half of the respondents (table 2).

Medical directors most commonly had formal responsibility to lead the guidelines strategy, but in four hospitals, no one did (table 3). In 19 hospitals, operational responsibility was devolved to people other than those with formal responsibility; of these, nine were doctors, five were nurses, and one a therapist; and most devoted up to a quarter of their salaried time to this task.

Table 4 shows the key elements reported as being considered in the written clinical guidelines strategies. Only $50 \%$ of strategies gave advice on the development of guidelines; and only a few made explicit statements on which clinical services should be targeted for guideline development, or the methods to be used for validation and the promotion of their uptake. Some strategies lacked explicit statements on methods to monitor adherence, routine review, and update of guidelines.

Most respondents $(89 \%, 31 / 35)$ said that their local guidelines were evidence-based. Various people were reported as having responsibility for validating guidelines including clinical teams $(42 \%, 15 / 36)$ and individual doctors $(22 \%, 8 / 36)$. However, $8 \%(3 / 36)$ of respondents reported that no one had such responsibility.

The most popular methods of validation were internal literature searches $(94 \%, 29 / 31)$, the use of national guidelines $(91 \%, 29 / 32)$, local consensus conferences $(88 \%, 28 / 32)$, and peer group review $(88 \%, 21 / 24)$. Five respondents reported that commissioned literature searches were used in their hospitals to validate local guidelines. 
Various measures were reported as being used to promote the dissemination, implementation, and evaluation of clinical guidelines. Those operating within the consultation between clinician and patient included the use of structured case notes (used in $45 \%, 14 / 31$, of the hospitals), patient mediated interventions $(35 \%, 9 / 26)$, and patient specific reminders $(31 \%, 8 / 26)$. Measures operating outside the consultation between clinician and patient included clinical audit $(97 \%, 31 / 32)$, peer review $(83 \%, 25 / 30)$, continuing education $(79 \%, 23 / 29)$, and the targeting of opinion leaders $(65 \%, 17 / 26)$. Financial or other incentives $(12 \%, 3 / 26)$ and financial or other sanctions $(8 \%, 2 / 26)$ were least used.

\section{Discussion}

Most senior staff in our survey thought that clinical guidelines were a good idea, and thought that development of local guidelines could improve patient care. Similarly favourable attitudes to the concept of clinical guidelines have also been reported in other studies. ${ }^{20-23}$ The criticism sometimes levelled at clinical guidelines as "cook book" medicine does not therefore seem to be shared by many healthcare professionals.

Some clinical guideline activity seems to be going on in most hospitals throughout the United Kingdom; but as only about one in five hospitals surveyed had a written clinical guidelines strategy, the bulk of this seems to be occurring in the absence of a locally agreed strategic framework.

The most important factor reported as influencing the development of a guidelines strategy was the need to improve clinical outcomes, suggesting that most hospitals with a strategy view guidelines primarily more as a means of enhancing clinical effectiveness than as a method of saving money. Only a few strategies seem to have explicitly considered the issue of development of clinical guidelines, and the three methods most commonly reported to validate local clinical guidelinesliterature searching, consensus, and the use of national guidelines - have considerable limitations. Literature searches through the usual databases - such as Medline-are unlikely to be sufficiently systematic to identify all the relevant evidence for evidence-based development of clinical guidelines, as these sources are not comprehensive. ${ }^{24}{ }^{25}$ Furthermore, the critical appraisal skills required to synthesise and interpret the evidence may not be locally available. $^{8}$

Clinical guidelines developed through informal consensus are often of poor quality, ${ }^{26}$ and consensus recommendations rarely lead to action. ${ }^{27}$ Also, the use of current national guidelines has major drawbacks: most are not evidence-based, and many do not satisfy the other desirable attributes of clinical guidelines. ${ }^{828}$

The essential skills and resources necessary to develop evidence-based clinical guidelines are rarely available locally or even regionally. ${ }^{8}{ }^{29}$ This perhaps explains why many locally produced guidelines, although having the decided advantage of "ownership" through the involvement of local users, are of poor quality. ${ }^{30} 31$

One way in which the lack of local expertise to develop good guidelines could be overcome is for developers of local guidelines to concentrate their efforts on identifying and adapting well validated national and regional guidelines for local use. ${ }^{89}$ We found considerable support for the concept of a national repository of evidence-based guidelines which hospital staff could access and adapt for local use. Such a facility would save considerable time and effort locally, would ensure that local guidelines were of high quality, would allow the positive features of local guidelines to be preserved, ${ }^{29}$ and would lead to a greater harmonisation in their use. The pressing need for a respected national body to assume responsibility for the development (and dissemination and implementation) of clinical guidelines has been previously highlighted. ${ }^{29}$

The lack of many strategies in our survey to explicitly consider the issues of dissemination, implementation, and evaluation of local guidelines, although disappointing, is perhaps not unexpected. Clinical guidelines are often poorly disseminated and implemented, ${ }^{23}{ }^{31-33}$ and as much (if not more) effort may need to be expended in making clinicians aware of and encouraging them to use the guidelines, than is required to develop them in the first place. ${ }^{34}{ }^{35}$ Similarly, evaluation of guidelines is often neglected, ${ }^{33}{ }^{36}$ but is essential to ensure that the desired clinical benefits of the guidelines are achieved, and to allow them to be regularly updated in the light of new evidence and experience.

\section{Conclusions}

Most senior hospital staff have a favourable attitude towards clinical guidelines. Most hospitals are undertaking some clinical guideline activity, but few seem to be doing so within locally agreed hospital wide strategies in which the issues of development, dissemination, implementation, and evaluation are being systematically considered.

Unless the situation has dramatically improved since we undertook the survey, our results lend support to the view that the development of evidence-based clinical guidelines should be considered at a national level. Hospitals should focus their efforts on the local adaptation, dissemination, implementation, and evaluation of such guidelines, and future local strategies should give clear guidance on how this is to be accomplished. Failure to do so is likely to mean that clinical guidelines will never achieve their full potential of improving clinical care and patient outcomes.

We are very grateful to those respondents who took the time to complete and return our questionnaire, and to the experts we consulted for their advice.

1 Institute of Medicine. In: Field MJ, Lohr KN, eds. Guidelines for clinical practice: from development to use. Washington, DC for clinical practice.from development 
2 Effective Health Care. Implementing clinical practice guidelines: can guidelines be used to improve clinical practice? guidelines: can guidelines be used to
Leeds: University of Leeds, 1994.

3 Grimshaw J, Freemantle N, Wallace S, et al. Developing and implementing clinical practice guidelines. Quality in Health Care 1995;4:55-64.

4 Grimshaw JM, Russell IT. Effect of clinical guidelines on medical practice: a systematic review of rigorous evaluations. Lancet, 1993;342:1317-22.

5 Grimshaw JM, Russell IT. Achieving health gain through clinical guidelines. I: developing scientifically valid guidelines. Quality in Health Care, 1993;2:243-8.

6 Hayward RSA, Wilson MC, Tunis SR, et al. Users' guides to the medical literature. VIII. How to use clinical practice guidelines. A. Are the recommendations valid? $¥ A M A$ guidelines. A. A

7 Wilson MC, Hayward RSA, Tunis SR, et al. Users' guides to the medical literature. VIII. How to use clinical practice guidelines. $B$. What are the recommendations and will the help you in caring for your patients? $\mathcal{F} A M A$ 1995;274: 1630-2.

8 Eccles M, Clapp Z, Grimshaw JM, et al. Developing valid guidelines: methodological and procedural issues from the North of England evidence based guideline developmen project. Quality in Health Care, 1996;5:44-50.

9 Grol R. Implementing guidelines in general practice care. Quality in Health Care 1992;1:184-91.

10 Grimshaw JM, Russell IT. Achieving health gain through clinical guidelines. II: ensuring guidelines change medical clinical guidelines. II: ensuring guidelines change

11 Thomson R, Lavender M, Madhok R. How to ensure that guidelines are effective. BMF 1995;311:237-42.

12 Ayres P, Renvoize T, Robinson M. Clinical guidelines: key decisions for acute service providers. British fournal of Health Care Management 1995;1:547-51.

13 NHS Management Executive. Improving clinical effectiveness. Leeds: Department of Health, 1993. (EL(93)115.)

14 NHS Management Executive. Improving the effectiveness of the NHS. Leeds: Department of Health, 1994. (EL(94)74.)

15 NHS Management Executive. Achieving an organisation wide approach to quality. Leeds: Department of Health, 1993. (EL(93)116.)

16 NHS Executive. Promoting clinical effectiveness. A framework for action in and through the NHS. Leeds: Department of Health, 1996.

17 Hopkins A. Some reservations about clinical guidelines Arch Dis Child 1995;72:70-5.

18 McKee M, Clarke A. Guidelines, enthusiasms, uncertainty, and the limits to purchasing. BMF 1995;310:101-4.
19 Directory of hospitals and NHS trusts 1994/5. Harlow: Churchill Livingstone, Longman, 1994.

20 Mansfield CD. Attitudes and behaviours towards clinical guidelines : the clinicians' perspective. Quality in Health Care, 1995;4:250-5.

21 Siriwardena AN. Clinical guidelines in primary care: a survey of general practitioners' attitudes and behaviour. $\mathrm{Br} \mathcal{F}$ Gen Pract 1995;45:643-7.

22 Newton J, Knight D, Woodhead G. General practitioners and clinical guidelines : a survey of knowledge, use, and beliefs. Br $\mathcal{f}$ Gen Pract 1996;46:513-7.

23 Gupta L, Ward JE, Hayward RSA. Clinical practice guidelines in general practice: a national survey of recall guidelines in general practice: a national survey of
attitudes and impact. Med $\mathcal{F}$ Aust 1997;166:69-72.

24 Adams CE, Power A, Frederick K, et al. An investigation of the adequacy of Medline searches for randomized controlled trials (RCTs) of the effects of mental health care. Psychol Med 1994;24:741-8.

$25 \mathrm{McD}$ onald SJ, Lefebvre C, Clarke MJ. Identifying reports of controlled trials in the $\mathrm{BMJ}$ and the Lancet. $B M F$ 1996;313:1116-7.

26 Woolf SH. Practice guidelines, a new reality in medicine II. Methods of developing guidelines. Arch Intern Med 1992;152:946-52.

27 Lomas J. Words without action? The production, dissemination, and impact of consensus recommendations. Annu Rev Public Health 1991;12:41-65.

28 Cluzeau F, Littlejohns P, Grimshaw JM. Appraising clinical guidelines: towards a "Which" guide for purchasers [editorial]. Quality in Health Care 1994;3:121-2.

29 Sudlow M, Thomson $R$. Clinical guidelines: quantity without quality. Quality in Health Care 1997;6:60-1.

30 Ward JE, Grieco V. Why we need guidelines for guidelines: study of the quality of clinical practice guidelines in Australia Med g Aust 1996;165:574-6.

31 Varonen H, Makela M. Practice guidelines in Finland: availability and quality. Quality in Health Care 1997;6:75-9.

32 Grol R. Implementing guidelines in general practice care. Quality in Health Care 1994;1:184-91.

33 Carter AO, Battista RN, Hodge MJ, et al. Report on activities and attitudes of organizations active in the clinical practice guidelines field. Can Med Assoc f 1995;153:901-7.

34 Delamothe T. Wanted: guidelines that doctors will follow. BMF 1993;307:218.

35 Haines A, Feder G. Guidance on guidelines. Writing them is easier than making them work. $B M f$ 1992;305:785-6.

36 Basinski ASH. Evaluation of clinical practice guidelines. Can Med Assoc F 1995;153:1575-81. 